\section{Package of products for the chemist}

\section{A. I. Scott}

Natural Product Reports: A Journal of Current Developments in Bio-organic Chemistry. Chairman of the editorial board G. Pattenden. Royal Society of Chemistry, London, UK. 6/yr. $£ 130$ (UK), $\$ 252$ (North America), £143 (elsewhere).

IN 1970 the Royal Society of Chemistry launched Specialist Periodical Reports which reviewed the literature of natural products on an annual or biennial basis. This series has now been discontinued and its place taken by the new bimonthly journal, Natural Product Reports.

The range of topics has been broadened from the original Reports on alkaloids, terpenoids and steroids, biosynthesis, and aliphatic and related natural product chemistry to include occasional accounts of chemotaxonomy, enzymology, biotechnology and spectroscopic techniques. The literature is usually covered for a twelvemonth period except in some of the more esoteric disciplines where a two-to-threeyear review is intended. Although the time lag for each article published is about twelve to eighteen months, the value of this publication to natural product chemists, whether in a university or industry, is unquestionable.

All is not perfect, however. In any journal the style and approach of the contributors will vary, and Natural Product Reports is no exception. We are presented with the whole spectrum, from terse, rather conventional compilations of data to almost chatty and, at times, biased views of a given field. While a degree of latitude in style is acceptable, the swing from uncritical to extremely rigorous reviewing can be misleading to those readers who wish to get into one of the natural

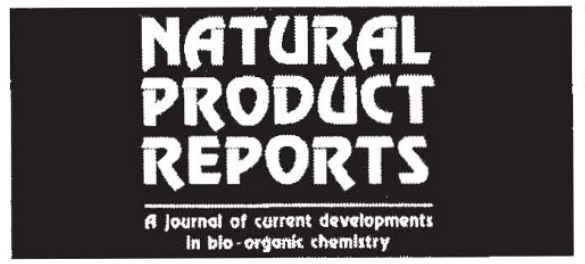

product areas outside their current interests. Indeed, one hopes that some kind of gentle refereeing process will be applied to those articles (only one in the first seven issues) which bear the marks of a parochial view of the field.

Nevertheless Natural Product Reports is a most welcome arrival. The reviews are not only comprehensive, but all one needs to know about a given subject is conveniently packaged in one journal and there is every opportunity to sample the flavour of natural product structures other than those of one's own favourite class. The subscription price may seem steep, but the collections of references and the clear structural formulae to be found in each issue are good value for money. Thus, many of the articles contain $250-300$ structures, and the topics covered in the seven issues available for review include 14 classes of alkaloids, all classes of terpenoids (and steroids), rotenoids, macrocyclic microbial metabolites, marine natural products, insect pheromones, biosynthesis of polyketides, terpenes, shikimate metabolites, porphyrins, chlorophylls and corrins, synthetic chemistry and an analytical method (droplet counter-current chromatography). An author and subject index appears annually, and a running cumulative index of authors and titles of

their reviews is provided in each issue.

The editorial board is to be commended for producing a publication which will be of great value in helping the natural product chemist keep track of the novel structures which appear in the literature at the rate of one every 400 minutes. Moreover the journal also includes periodic reviews of those techniques which are revolutionizing the isolation and structural elucidation of the compounds of nature, a feature which many will find useful.

A. I. Scott is Davidson Professor of Science in the Department of Chemistry, Texas $A \& M$ University, College Station, Texas 77843, USA.

\section{Across the divide}

\section{Ian M. Mills}

Soviet Journal of Chemical Physics. Editor-in-chief N.N. Semenov. Gordon \& Breach. 12/yr. UK £546 (corporate), £464 (institutional), £232 (individual); North America $\$ 656$ (corporate), $\$ 558$ (institutional), $\$ 279$ (individual).

CHemical physics in the Soviet Union has a wonderful parentage, in the eyes of Western scientists, through the remarkable series of monographs written by Landau and Lifshitz, which have been available in English translation from Pergamon Press for many years. These volumes, which comprise a complete "course in theoretical physics", are the most authoritative and comprehensive set of textbooks on the subject; they are useful both for teaching and for reference, and they set a high standard in every way. I see them as a shining example of the international nature of science, and expect to find a similarly high standard of chemical physics in the Soviet Union.

Yet the truth is that most of us know little of current efforts in this field in Rus sia, and there are few references to Soviet research in the Western literature. Is there good work being done there, but unknown to us in the West because of the language barrier? If so, this new journal, a cover-to-cover translation of Khimicheskaya Fizika, will be invaluable in helping to bridge the language and cultural gap between Western and Eastern scientists

The English translation is nicely produced, in a small A5 page format, and covers some 3,000 pages per year; however it appears rather more than a year after the original Russian publication. The subject matter seems to span the full area of chemical physics, from the physics and chemistry of polymers, through electron tunnelling in chemistry, to molecular energy relaxation in gas discharges. Both theory and experiment are represented, with theory perhaps predominant (as is probably the case in Western journals).
Yet the papers have a dated look in comparison to those appearing in, for example, the American Physical Society's Journal of Chemical Physics; they tend to be shorter and more general than the papers we see in the West. Above all there is no evidence of the influence of computers: $a b$ initio calculations, tables of numerical data and all kinds of high-resolution spectra are noticeably absent. The theoretical contributions tend to concentrate on the derivation and discussion of analytical formulae.

Another point of interest is the references. About a third of the papers cite

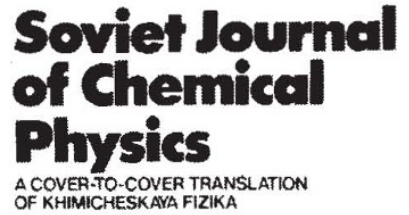

only Russian work and the remainder have rather more Russian than Western references. It hardly seems likely that this reflects the proportion of research in the field, and one must conclude that the communication barrier is as great West to East as it is East to West.

This new journal must be welcomed as providing another channel across the divide, for those who can afford to pay the price (which seems high. even to our institution libraries). However looking through it leaves me with the impression that chemical physics in the Soviet Union is far behind similar work in the West, despite the heritage of Landau and Lifshitz.

Ian M. Mills is Professor of Chemical Spectroscopy in the Department of Chemistry, University of Reading. Whiteknights, Reading $R G 62 A H$. UK.

\section{Journal prices}

Details of editors and frequency of publication, and the subscription rates appearing at the top of each review, are given in most instances for 1986. This information is not complete in all cases. and readers interested in subscribing to a particular journal should check the rates with the publisher concerned. 